\title{
Organic Manures Improved the Phenolic Content, Antioxidant Capacity and Soluble Solids in Pepper
}

\author{
Alejandro Moreno-Reséndez1,2,3*, Ricardo Parcero-Solano1, José Luis Reyes-Carrillo1,2, \\ Lilia Salas-Pérez ${ }^{3,4,5}$, María del Rosario Moncayo-Luján3,4,5, Mercedes Georgina Ramírez-Aragón3,4,5, \\ Norma Rodríguez-Dimas ${ }^{1}$
}

${ }^{1}$ Universidad Autónoma Agraria Antonio Narro, Unidad Laguna, México

${ }^{2}$ Integrantes del Cuerpo Académico de Sistemas Sustentables para la Producción Agropecuaria (CASISUPA) de la UAAAN, Key: UAAAN-CA-14, Torreón, México

${ }^{3}$ Integrantes de la Red Académica de Innovación en Alimentos y Agricultura Sustentable (RAIAAS), Consejo Estatal de Ciencia y Tecnología del Estado de Coahuila de Zaragoza, Comunidad de Instituciones de Educación Superior de la Laguna (COECYT-CIESLAG), Torreón, México

${ }^{4}$ Universidad Politécnica de Gómez Palacio, Gómez Palacio, México

${ }^{5}$ Integrantes del Cuerpo Académico Ingeniería en Biotecnología y Administración de Negocios Internacionales, Key: UPGOP-CA-1, Gómez Palacio, México

Email:*alejamorsa@yahoo.com.mx

How to cite this paper: Moreno-Reséndez, A., Parcero-Solano, R., Reyes-Carrillo, J.L., Salas-Pérez, L., Moncayo-Luján, M.R., Ramírez-Aragón, M.G. and RodríguezDimas, N. (2016) Organic Manures Improved the Phenolic Content, Antioxidant Capacity and Soluble Solids in Pepper. Fooa and Nutrition Sciences, 7, 1401-1413. http://dx.doi.org/10.4236/fns.2016.714127

Received: December 1, 2016

Accepted: December 26, 2016

Published: December 29, 2016

Copyright (c) 2016 by authors and Scientific Research Publishing Inc. This work is licensed under the Creative Commons Attribution International License (CC BY 4.0).

http://creativecommons.org/licenses/by/4.0/ (c) (i) Open Access

\begin{abstract}
The aim of this research was to determine the effect of three organic manures (vermicompost, simple compost, compost with gypsum) with four different levels, as sources of fertilization, and mixed with river sand, this was used as an inert material, on the phenolic content, antioxidant capacity and total soluble solids of bell peppers (Capsicum annuum L.). The 12 mixtures formulated, with eight replications, were distributed in a completely randomized design. Data were statistically analyzed by analysis of variance and means were compared by test Tukey ${ }_{5 \%}$. All variables were significantly affected $(\mathrm{p} \leq 0.001)$. Fruits with highest phenolic content were developed in the mixtures M2, M5 and M6 with 538.76, 541.54 and $565.04 \mathrm{mg}$ GAE $100 \mathrm{~kg}^{-1} \mathrm{DW}$, respectively. Antioxidant capacity of fruits was increased with mixtures M2, M5, M6 and M7 with values of 934.48, 942.04, 921.69 and $924.17 \mu \mathrm{M}$ TEAC $\cdot \mathrm{g}^{-1} \mathrm{DW}$, respectively. The soluble solids content was higher in mixtures M1 and M2 with values of 4.93 and $4.97{ }^{\circ}$ Brix, respectively. It was concluded that the variables studied were favored when applying, as sources of fertilization, mixtures of these organic manures with river sand, which could represent a suitable alternative for food production with quality nutraceutical.
\end{abstract}

\section{Keywords}

Organic Agriculture, Capsicum annuum, Phenolic Compounds, Antioxidant 
Capacity, Soluble Solids

\section{Introduction}

Industrial agriculture depends on expensive inputs from off the farm (e.g., pesticides and fertilizer), many of which generate wastes that harm the environment; it uses large quantities of nonrenewable fossil fuels; and it tends toward concentration of production, driving out small producers and undermining rural communities [1]. On the other hand, nowadays, consumers are more concerned a possible exposure to agrochemical products, especially in those food that are consumed fresh [2] and they prefer products that are free from chemical, insect or mechanical injuries [3]. Additionally it is widely acknowledged that, food production and their consumption have implications on human health and also have a great impact on environment [4]. In this sense, during the last decades, consumers and researchers have become increasingly interested in a healthier diet, by increasing the intake of fruit and vegetables, mainly because these foods are an important source of bioactive compounds [5] and their intake can be important to prevent degenerative diseases [6].

Regarding the above, several authors have suggested that the use of organic manures or organic fertilizers, e.g., compost and vermicompost, are an essential source of nutrients for sustainable agriculture [7], and as sources of nutrients, in addition to covering the physiological requirements of crops, favor the development of high quality fruits [2] [8]. Likewise, Faezah-Omar et al. [8] concluded that organic fertilizer should be used in place of chemical fertilizer for better quality cassava (Manihot esculenta Crantz) because of the application of vermicompost and compost, due to enhancing the antioxidant activity of this crop. Similarly, Ibrahim et al. [9] observed that the application of organic fertilizer enhanced the production of total phenolics, flavonoids, ascorbic acid, saponin and gluthathione content in Labisia pumila Benth. \& Hook. f., compared to the use of inorganic fertilizer. Antioxidant activity of bell peppers, and of another fruits and vegetables, depends on several factors including genetic environmental condition (temperature, light, water, and nutrient availability), production techniques used (plant grow regulators, date of harvest, etc.) and post harvest storage conditions [10] [11]. According to this, it is more appropriate to express the antioxidant concentrations relative to the DW, because the main factors involved often also affect the DW content [10].

On another hand, there are many factors that influence in the fruit quality, these include fruit size (weight), fruit firmness and soluble solids [12]. The total soluble solids (TSS) showed high positive correlation with sugars content and was therefore generally accepted as an important quality trait of fruits [13], and sugars content is often used as an index of ripening [14]. In addition, the sugar content of plants has been linked to formation of non-structural carbohydrates that are used for the synthesis of phenolic compounds and antioxidants [15] [16]. 
Diverse studies have demostrated that peppers, consumed in fresh form, processed or as spice in some dishes around the world [17], contain a wide array of phytochemicals [18] which contribute to a high antioxidant activity and may be considered as a good source of natural antioxidants [17] [19]. Nevertheless, studies of peppers with organic and inorganic sources of fertilization have been mainly focused on their productive characteristics and its content of bioactive nutrients or compounds with antioxidant properties not has been widely studied, specially with the use of organicmanures application [2]. As described in the preceding paragraphs, it could be suggested that, development and nutraceutical quality of the crops under greenhouse conditions and traditionally subject to use of nutrient solutions, might be satisfied with the use of organic manures, thus reducing employment of synthetic fertilizers. Therefore, the objective of this study was to evaluate the effect of three organic manures [vermicompost (VC), simple compost (SC), compost with gypsum (CG)] with four different levels, as sources of fertilization, and mixed with river sand (RS), this was used as an inert material, on the phenolic content, antioxidant capacity and TTS of peppers.

\section{Materials and Methods}

\subsection{Experimental Conditions}

The experiment was accomplished at the Universidad Autónoma Agraria Antonio Narro-UL in Torreón, Coahuila, México $\left(101^{\circ} 40^{\prime} \mathrm{W}\right.$ and $104^{\circ} 45^{\prime} \mathrm{W}$ and $25^{\circ} 05^{\prime} \mathrm{N}$ and $26^{\circ} 54^{\prime} \mathrm{N}$ ) [20]. The experiment was performed into a cenital greenhouse with semiautomatic temperature regulator. Temperature and humidity values were kept between $25^{\circ} \mathrm{C}-30^{\circ} \mathrm{C}$ and $70 \%-80 \%$, respectively. It was used seeds: Mecate $\mathrm{F} 1$ variety (Harris Moran Seed Company ${ }^{\oplus}$ ), which were sown on January 23, 2013, in polystyrene trays of 200 cavities, using Peat Moss (Canadian Sphagnum Peat Moss Association ${ }^{\circledR}$ ) as substrate, which were previously saturated with water, then filled the tray and deposited two seeds per cavity. The trays were placed inside the greenhouse, covered with black plastic and watered with tap water [pH 7.57], RAS 2.18 and EC $1.05 \mathrm{dS} \cdot \mathrm{m}^{-1}$, classified as C1S1, with low risk of salinization and alkalinization [21] every three days until the time of transplant, which was performed on Febraury 20, 2013, when the plant had an approximate height of $15 \mathrm{~cm}$ and they had five to six true leaves, placing one seedling per pot.

The cultivation of pepper was developed using three organic manures (VC, SC and CG) in different mixtures with RS, the sand was used as an inert material [22], with ratios 1:1, 1:2, 1:3 and 1:4, by volume (Table 1). The VC was prepared using horse manure, rabbit and goat straw mixed with alfalfa (Medicago sativa L.) in a ratio 1:1:1 by volume, and earthworms Eisenia fetida Savigny [23] for a period of 90 days [24]. SC and CG were purchased from the company MaxCompost Orgánico ${ }^{\oplus}$, the chemical composition of these fertilizers is presented in Table 2. The sand used in the mixtures was previously disinfected using a solution of water and chlorine at $5 \%$.

The different mixtures of organic manures and sand were placed in black polyethylene $20 \mathrm{~kg}$ capacity bags (gavels). The gavels were placed in a line to double array 
Table 1. Mixtures of organic substrates with river sand evaluated during the development of pepper, in greenhouse conditions.

\begin{tabular}{cccc}
\hline Components (M) & Components (M) & Components (M) & Ratio (v:v) \\
\hline VC:RS (M1) & SC:RS (M5) & CG:RS (M9) & $1: 1$ \\
VC:RS (M2) & SC:RS (M6) & CG:RS (M10) & $1: 2$ \\
VC:RS (M3) & SC:RS (M7) & CG:RS (M11) & $1: 3$ \\
VC:RS (M4) & SC:RS (M8) & CG:RS (M12) & $1: 4$ \\
\hline
\end{tabular}

$\mathrm{M}=$ Mixture (M1 - M12); VC = Vermicompost; $\mathrm{SC}=$ Simple Compost; $\mathrm{CG}=$ Compost with Gypsum; RS = River Sand; v:v = volume:volume.

Table 2. Chemical analysis of the organic substrates used during the development of pepper, in greehhouse conditions.

\begin{tabular}{ccccccccccccc}
\hline & $\mathrm{EC}$ & & $\mathrm{N}$ & $\mathrm{P}$ & $\mathrm{K}$ & $\mathrm{Ca}$ & $\mathrm{Mg}$ & $\mathrm{Cu}$ & $\mathrm{Fe}$ & $\mathrm{Zn}$ & $\mathrm{Mn}$ \\
\hline & $\left(\mathrm{dS} \cdot \mathrm{cm}^{-1}\right)$ & $\mathrm{pH}$ & $(\%)$ & \multicolumn{7}{c}{$\left(\mathrm{mg} \cdot \mathrm{kg}^{-1}\right)$} \\
\hline $\mathrm{VC}$ & 7.1 & 7.9 & 0.95 & 2229.7 & 611.8 & 48.6 & 5.6 & 1.8 & 26.0 & 12.0 & 21.2 \\
$\mathrm{SC}$ & 37.8 & 7.7 & 0.96 & 2254.9 & 682.8 & 19.1 & 6.2 & 4.5 & 23.1 & 11.1 & 20.6 \\
$\mathrm{CG}$ & 41.72 & 7.6 & 1.77 & 2269.1 & 623.7 & 50.3 & 4.5 & 5.2 & 22.5 & 10.4 & 19.8 \\
\hline
\end{tabular}

VC = Vermicompost; $\mathrm{SC}=$ Simple Compost $\mathrm{CG}=$ Compost with Gypsum.

and "tresbolillo" arrangement, with a distance between plants $30 \mathrm{~cm}$. The experimental unit consisted of a gavel, with one plant per gavel, with eight replicates per treatment. The crop was trained one stem with two branches, removing the lateral buds, with raffia threads, it was bundle to the structure of the greenhouse. For water supply we used drip irrigation in all mixtures and the amount of water applied, according to the phenological stage of the crop, ranged from 0.5 to $1.5 \mathrm{~L} \cdot$ plant $^{-1} \cdot$ day $^{-1}$.

The harvest of the fruits, one by each repetition was made when they reached their full development, the indicators considered for this activity were the size, color, consistency of the fruit and maturation the fruits when they showed approximately $25 \%$ of the mature hue [25]. The fruits were washed in tap water for 2 min to remove residues of the mixtures. They were dried on blotting paper, at the shade and room temperature $\left(30^{\circ} \mathrm{C} \pm 2^{\circ} \mathrm{C}\right)$ for 25 days. Upon completion of this period, only the pericarp of fruits was manually grinded (using a mortar and pestle) and the ground material was deposited in plastic tubes, previously identified, and were stored in ultra freezer at $-80^{\circ} \mathrm{C}$, until obtain the extract.

\subsection{Pepper Extracts}

The extracts were obtained by a mix $10 \mathrm{mg}$ dried sample in $10 \mathrm{~mL}$ of $80 \%$ methanol in plastic tubes with screw cap, they were placed in Rotary shaker (ATR Inc., USA. ${ }^{\circ}$ ) for 3 $\mathrm{h}$, at $20 \mathrm{rpm}$ at $5^{\circ} \mathrm{C}$. The tubes were then centrifuged at $3000 \mathrm{rpm}$ for $5 \mathrm{~min}$, and supernatants were extracted for analysis. Reagents for the analysis were as follow: FolinCiocalteu reactive, gallic acid, $\mathrm{NaCO}_{3}$, Trolox, 2,2-Diphenil-1-pycril hydrazyl hydrate (DPPH, 95\% purity), ethanol and methanol. All chemicals were purchased from SigmaAldrich (St. Louis, MO). 


\subsection{Total Polyphenols}

Total phenolic content was measured using a modification of Folin-Ciocalteu method [26]. $30 \mu \mathrm{L}$ of extract were mixed with $270 \mu \mathrm{L}$ of distilled water in a test tube. Next 1.5 $\mathrm{mL}$ of Folin-Ciocalteu reagent (Sigma-Aldrich, St. Louis MO, USA) diluted (1:15) were added to mixture, with stirring vortexed for $10 \mathrm{~s}$. After 5 minutes was added $1.2 \mathrm{~mL}$ of sodium carbonate $[7.5 \%(\mathrm{w} / \mathrm{v})]$ and stirred for $10 \mathrm{~s}$. The solution was placed in water bath at $45^{\circ} \mathrm{C}$ for $15 \mathrm{~min}$, and then allowed to cool to room temperature. Absorbance of the solution was read at $765 \mathrm{~nm}$ on a Genesys $10 \mathrm{UV}$ spectrophotometer ${ }^{\circledR}$. Phenolic content was calculated using a calibration curve using gallic acid as standard, and the results were reported in milligrams of gallic acid equivalent per 100 gram of dry weight (mg GAE$\cdot 100 \mathrm{~g}^{-1} \mathrm{DW}$ ). Analyses were performed in triplicate.

\subsection{Determination of Antioxidant Activity}

Determination of total antioxidant capacity (TAC) of the different samples was conducted based on the method of Molyneux [27] with slight modifications. The free radical 1,1-diphenyl-2-picryl-hidrazilo $\left(\mathrm{DPPH}^{+}\right.$) solution (Aldrich, St. Louis MO, USA) was prepared in a completely covered with foil flask with $\mathrm{DPPH}^{+} 5 \mathrm{mg} \cdot 100 \mathrm{~mL}^{-1}$ of ethanol analytical grade. The flask with the sample was stirred vigorously and it remained covered to prevent rapid degradation of the sample. The $300 \mu \mathrm{L}$ sample of the diluted extract in test tubes in triplicate and $1200 \mu \mathrm{L}$ of distilled water being stirred at $3000 \mathrm{rpm}$ for $10 \mathrm{~s}$. Then $1.0 \mathrm{~mL}$ of $\mathrm{DPPH}^{+}$was added and stirred again vortexed at $3000 \mathrm{rpm}$ for $10 \mathrm{~s}$. Readings were made at $517 \mathrm{~nm}$ after 90 minutes. The TAC was calculated using a standard curve with the reference antioxidant Trolox and results were expressed in $\mu \mathrm{M}$ Trolox Equivalent Antioxidant Capacity per gram of dry weight $\left(\mu \mathrm{M} \mathrm{TEAC} \cdot \mathrm{g}^{-1} \mathrm{DW}\right)$.

\subsection{Quantification of Total Soluble Solids}

A refractometer (Master-T, ATAGO ${ }^{\circledR}$ ) was used to quantify this variable, in which two drops of juice fruit were placed on glass of reading of the refractometer and the soluble solids were determined in ${ }^{\circ}$ Brix.

\subsection{Statistical Analysis}

The mixtures (treatments) were distributed in a completely randomized design with eight replications. The variables data were analyzed by analysis of variance and means were separated by test Tukey $(\mathrm{p}<0.05)$ using the statistical software of Olivares-Saenz [28].

\section{Results and Discussion}

\subsection{Total Phenolic Compounds}

In general, high levels of total phenols were found in the pepper fruits of hybrid Mecate F1. The results of this study showed highly signifcant differences $(P \leq 0.001)$ for content of total phenolic compounds (CTPC) due to effect of mixtures of different 
organic manures with RS (Figure 1). For this variable it was registered a mean value of $467.959 \mathrm{mg} \mathrm{GAE} \cdot 100 \mathrm{~g}^{-1} \mathrm{DW}$, with a coefficient variation of $4.03 \%$. The highest CTPC were recorded in the mixtures M2, M5 and M6 with values of 538.76, 541.54 and 565.04 mg GAE $100 \mathrm{~g}^{-1}$ DW, respectively (Figure 1). The higher levels of the CTPC were obtained utilizing only the pericarp of fruits, that the seeds were removed from these already. On the other hand, the smaller phenolic content was registered in fruits obtained in the mixture M1 [VC:RS (1:1)] with a value of $350.94 \mathrm{mg} \mathrm{GAE} \cdot 100 \mathrm{~g}^{-1} \mathrm{DW}$.

According with Hallmann and Rembiałkowska [19] the use of organic manures mixed with RS favoured the CTPC in fruits of pepper. The values 538.76, 541.54 and $565.04 \mathrm{mg}$ GAE $100 \mathrm{~g}^{-1} \mathrm{DW}$, registered in the mixtures M2, M5 y M6, respectivaly, outperformed in at least for a $2.0 \%$ of phenolic content of peppers developed in the rest of mixtures evaluated. Also, these concentrations were overcome, in at least 9.07\% compared to the CTPC reported by Helmja et al. [29] in chili pepper, that was acquired at the local market of Estonia during autumn of 2006 and 2007. Equally, these values were similar to results reported by Navarro et al. [30] in the fruits of pepper cv. Orlando, with an average of $538 \mathrm{mg}$ GAE$\cdot 100 \mathrm{~g}^{-1} \mathrm{DW}$, when they applied a nutrient solution and three levels of salinity with $\mathrm{NaCl}(0,15$ and $30 \mathrm{mM})$.

The CTPC which ranged from 350.94 and $565.04 \mathrm{mg} \mathrm{GAE} \cdot 100 \mathrm{~g}^{-1} \mathrm{DW}$, that were fertilized exclusively with three organic manures, VC, SC and CG, surpassed, in at least, $70.58 \%, 47.71 \%, 12.10 \%$ to CTPC of the fruits of Yellow Bell 47 (green) reported by Medina-Juárez et al. [17], pepper cv. Oregon reported by Tzortzakis et al. [31], and Bell pepper registered by Howard et al. [18], respectively. In the same way, the interval of

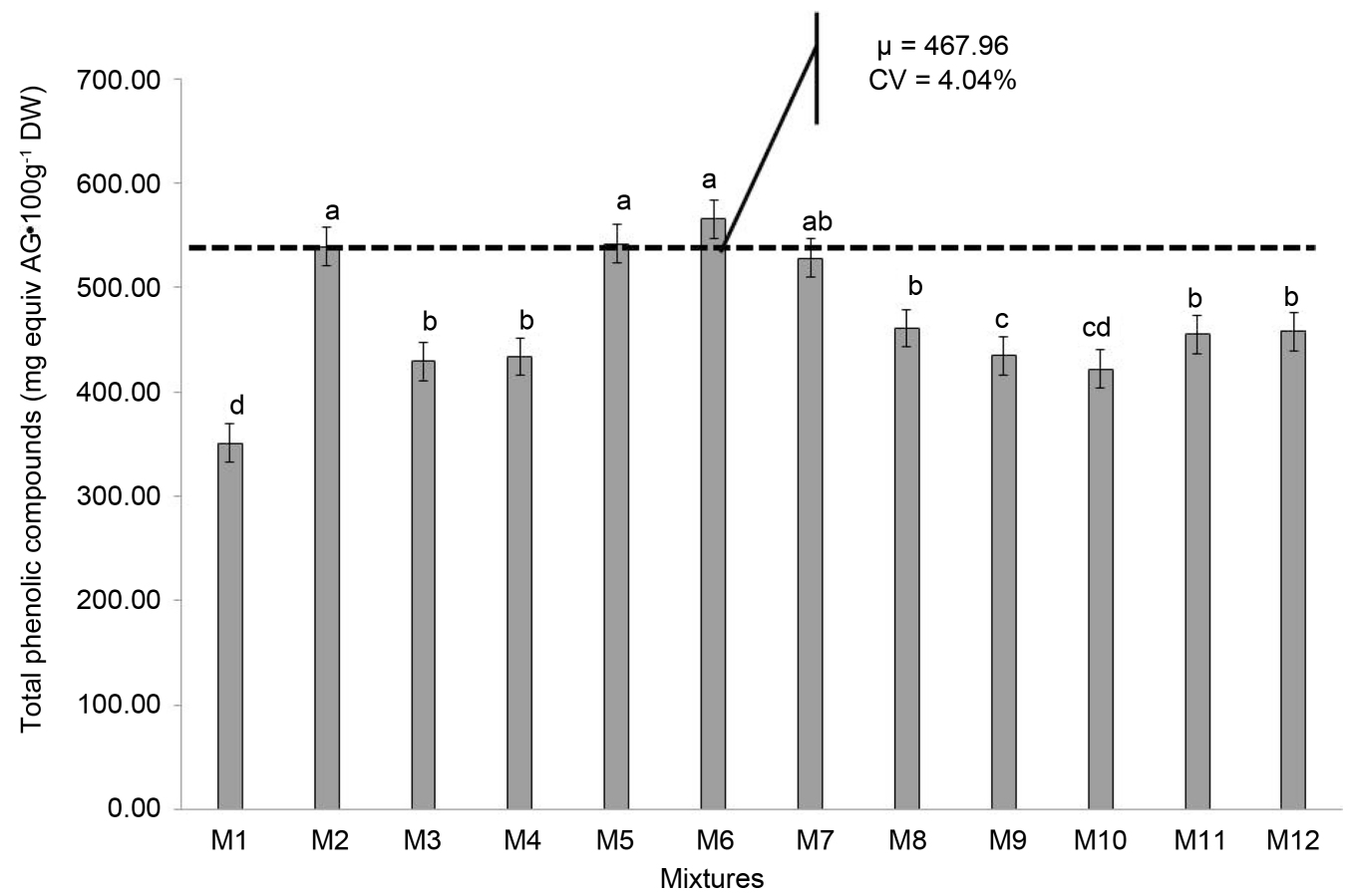

Figure 1. Total phenolic compounds in pepper development in different organic substrates under greenhouse conditions. Columns with the same letter are statistically similar, according to the Tukey test at $5 \%$. 
values, 350.94 and $565.04 \mathrm{mg}$ GAE$\cdot 100 \mathrm{~g}^{-1} \mathrm{DW}$ surpassed, in at least, in a $15.65 \%$ to CTPC reported by Kevers et al. [32], because they determined values of 296, 284 y 251 mg GAE $100 \mathrm{~g}^{-1} \mathrm{DW}$, for red, yellow and green peppers, respectively. Even though, it is well known that content of phytochemicals, including phenolic compounds present in vegetables, is affected by the specie and type of pepper, agronomic conditions, maturity, postharvest handling and pre and postharvest treatments applied to the fruit [17], in this experiment, which has registered a high CTPC in green peppers, it could be due to the agronomic management conditions among which the application of three organic manures was included.

\subsection{Antioxidant Activity}

The results of this study also showed highly significant differences $(P \leq 0.001)$ for antioxidant activity due to the effect of mixtures of different organic manures with RS (Figure 2). For this variable it was registered a general average of $755.34 \mu$ Mequiv Trolox. $\mathrm{g}^{-1} \mathrm{DW}$, with a variation coefficient of $1.54 \%$. The highest content of TAC were recorded in the mixtures M2, M5, M6 and M7 with values of 934.48, 942.04, 921.65 and $924.17 \mu$ Mequiv Trolox $\cdot \mathrm{g}^{-1} \mathrm{DW}$, respectively (Figure 2 ). These values outperformed in at least for a $20.38 \%$ to the TAC of peppers developed in the rest of mixtures evaluated. The smaller TAC was recorded in fruits developed in the mixtures M1 and M9 with values of 587.40 and $617.18 \mu$ Mequiv Trolox $\cdot \mathrm{g}^{-1} \mathrm{DW}$, respectively.

In accord with Díaz-Méndez et al. [33] the use of VC has proven its potential as an alternative nutritional source for organic production of cucumber (Cucumis sativus L.)

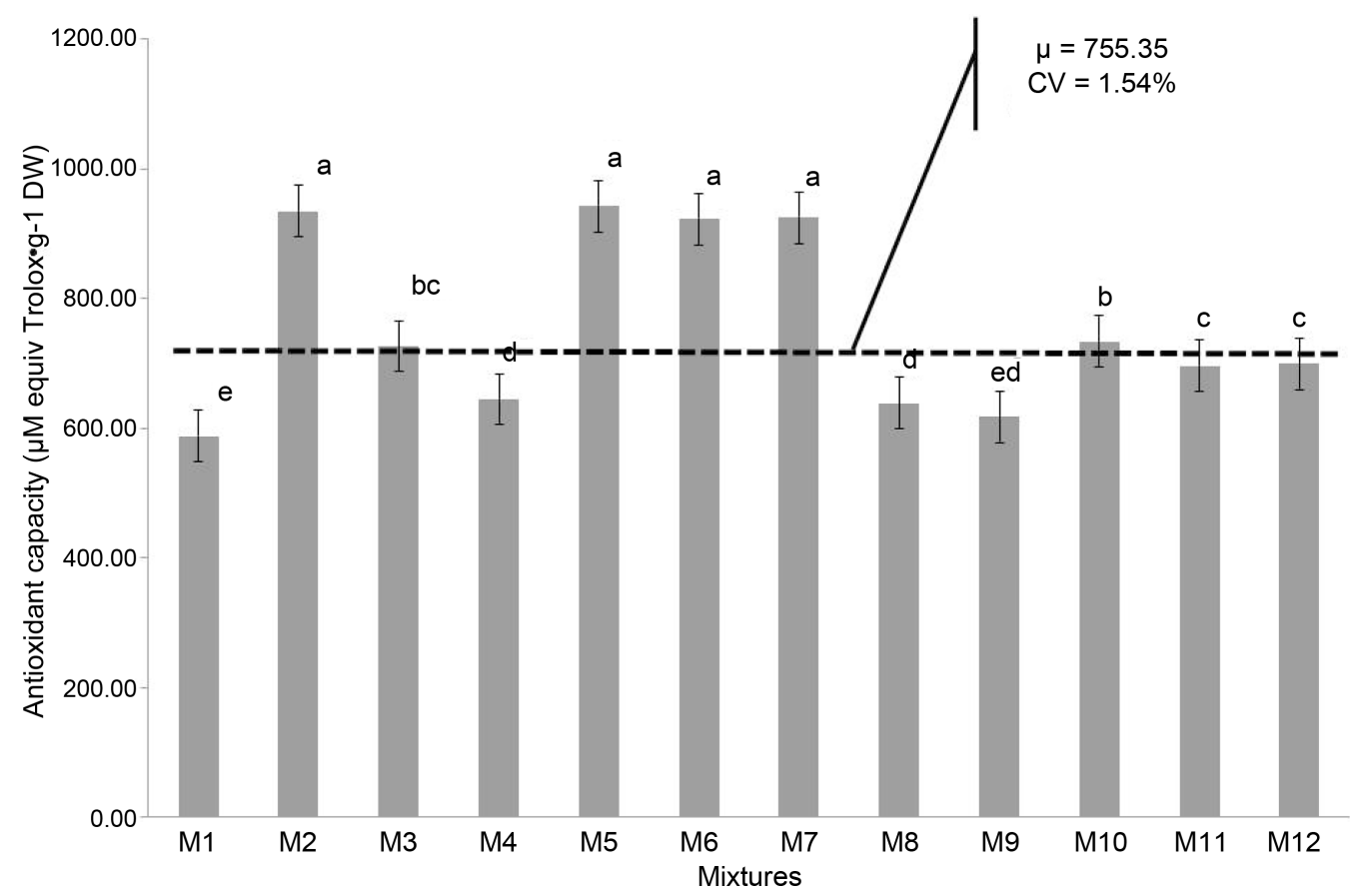

Figure 2. Antioxidant capacity (AC) in pepper development in different organic substrates under greenhouse conditions. Columns with the same letter are statistically similar, according to the Tukey test at $5 \%$. 
with high antioxidant capacity, under greenhouse conditions. Additionally, Hallmann and Rembialkowska [19] concluded that an organic growing system, compared with conventional system, increased the level of antioxidant compounds in fuits of sweet bell pepper.

The TAC of fruits in this experiment which ranged from 587.40 to $942.04 \mu$ Mequiv Trolox. $\mathrm{g}^{-1} \mathrm{DW}$ and that were ferilized exclusively with three organic manures, VC, SC and CG, was considerably greater than the average value of $47.63 \mu$ Mequiv Trolox $\cdot \mathrm{g}^{-1}$ DW, registered by Alvarez-Parrilla et al. [34] in four fresh Jalapeño and Serrano peppers, purchased at a local supermarket at Ciudad Juárez, Chihuahua, México. The range of TAC determined also was considerably greater than the value of $34.44 \pm 0.43$ $\mu$ Mequiv Trolox $\cdot \mathrm{g}^{-1}$ fresh weight (FW), reported by Medina-Juárez et al. [17] in Bell peppers extracts. Although these authors highlight that this value reflects a high antioxidant capacity in the aqueous extract from the fruits of peppers, at least with regard to the results obtained in the present experiment, this value was considerably smaller.

Likewise, the range mentioned was considerably higher than the range of $62-108$ $\mu$ Mequiv Trolox $\cdot \mathrm{g}^{-1} \mathrm{FW}$, determined by Blanco-Ríos et al. [35] in four commercially cultivars of fresh pepper (green, red, orange and yellow) $c v$. Orion, Mazuca, Simpaty and Taranto, respectively, these peppers were grown in a greenhouse with similar conditions of temperature, humidity and fertilizer (nutrient solution). The foregoing strengthens the fact that organic manures may be considered as an alternative nutritional source with a great potential to increase the levels of antioxidant capacity of fruits and vegetables [19] [33].

The range obtained also outperformed to the average of $538 \mathrm{mg} \mathrm{GAE} \cdot 100 \mathrm{~g}^{-1} \mathrm{DW}$, reported by Navarro et al. [30] in the fruits of pepper $c v$. Orlando, when they applied nutrient solution and three levels of salinity with $\mathrm{NaCl}(0,15$ and $30 \mathrm{mM})$ and concluded that a moderate salinity causes a significant increase in the antoxidant capacity of peppers, as a natural defense mechanism of tissue against the stress. In this experiment at least in the VC was registered a moderate salinity (Table 2). Nevertheless although, the salinity seems to be the major limiting factor to the use of large amounts of compost as a growth-media component [31], under the conditions in which the experiment was carried out and because of the results obtained, it emphasizes that the EC of the three organic manures, had no adverse effect on evaluated variables. Finally, as provided in the foregoing paragraphs it is feasible, according to Medina-Juarez et al. [17], emphasize that the antioxidant capacity depends of growing conditions, fruit maturity and the pepper type.

\subsection{Total Soluble Solids}

For TSS were showed highly signifcant differences $(P \leq 0.001)$ due to the effect of mixtures of different organic manures with RS. For this variable it was registered a mean value of $4.16^{\circ} \mathrm{Brix}$, with an variation coefficient of $19.07 \%$. The highest content of TSS was recorded in the mixtures M1 and M2 with values of 4.93 and $4.79{ }^{\circ}$ Brix, 
respectively. Lastly, the smaller TSS was recorded in fruits developed in the mixture M3 with $3.06{ }^{\circ}$ Brix (Figure 3).

The average recorded for TSS exceded by at least a $27.36 \%$ to the average value reported by Tzortzakis et al. [31] at fruits of pepper $c v$. Oregon, in assessing the effects of municipal solid waste compost (MSWC) mixed with soil, in different ratios, without fertigation. Aditionally, this average was similar to the mean value of $4.26{ }^{\circ} \mathrm{Brix}$, determined by Aminifard et al. [36] in fruits of sweet pepper $c v$. California Wonder, developed under in field, whose fertilization consisted of four levels of compost $(0,5,10$ and $15 \mathrm{t} \cdot \mathrm{ha}^{-1}$ ) and their conclusion was that fruits harvested from plants that received compost had significantly greater TSS than those harvested from the mineral fertilizer plots. In a similar way, the mean of $4.16^{\circ}$ Brix was analogous to the average of $4.6 \pm 0.3$ and $4.7 \pm 0.4{ }^{\circ}$ Brix, registered by Chassy et al. [37] in fruits of bell peppers, $c v$. California Wonder and Excalibur, respectively, grown under organic conditions over a 3 -year period. Equally, the average of TSS found in this experiment was relatively low in comparing to the range, 5.2 to $6.6^{\circ}$ Brix, obtained by Abu-Zahra [38] in an study of sweet pepper fruits, $c v$. Barotte, produced under conventional and organic systems. A similar behavior was reported by Fawzy et al. [39] with sweet pepper cv. California Wonder, whose TSS ranged between 5.2 and $6.6^{\circ}$ Brix, developed with different combination of mineral nitrogen, organic (chicken manure) as well as biofertilizer (Microbin and Biogen), under field conditions. The differences that were registered in the values of TSS could be due to differences between the used cultivars.

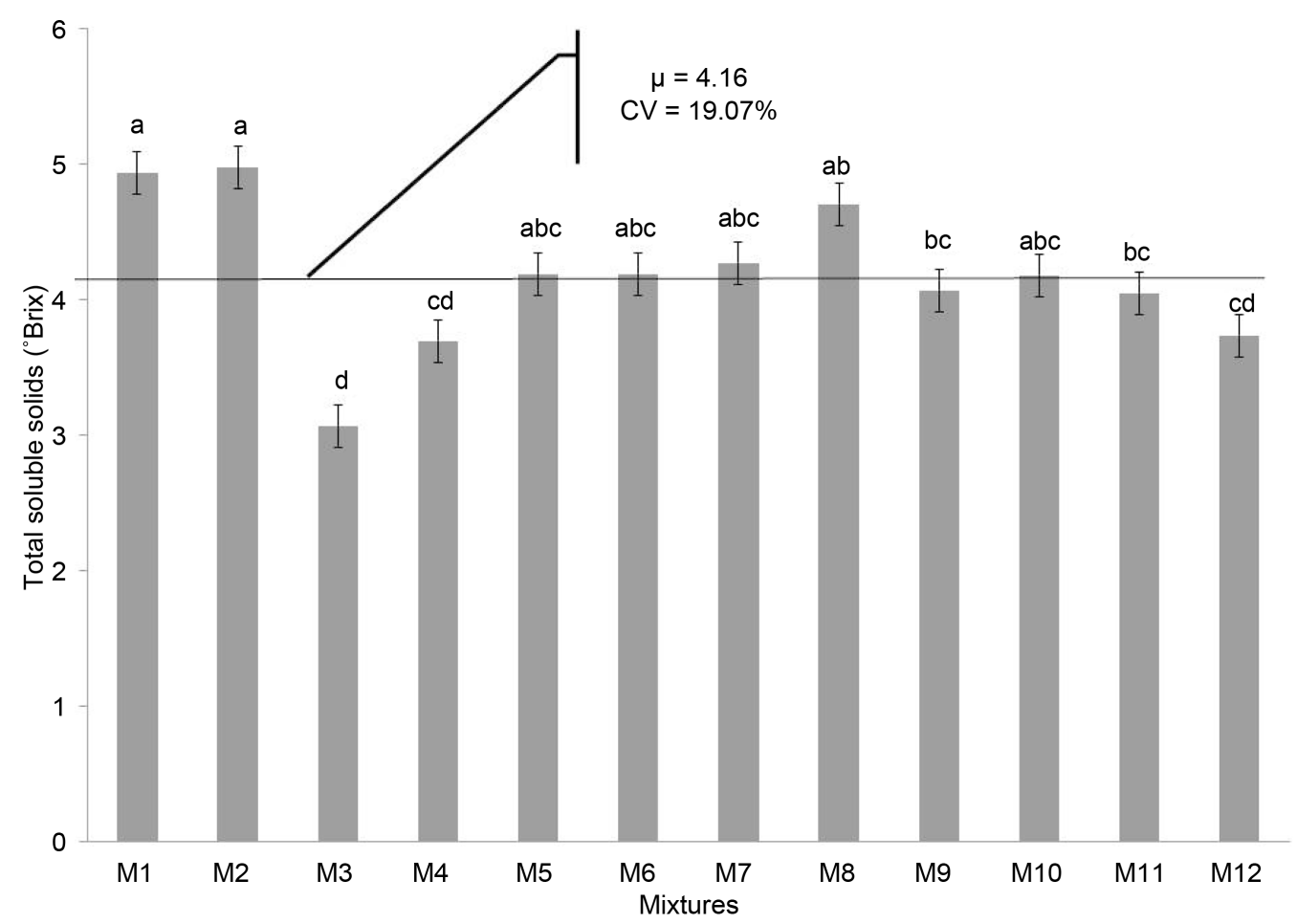

Figure 3. Total soluble solids in pepper development in different organic substrates under greenhouse conditions. Columns with the same letter are statistically similar, according to the Tukey test at $5 \%$. 
The range of 4.93 and $4.79{ }^{\circ}$ Brix, obtained in the present experiment outperformed in at least for a $4.66 \%$ to the TSS of fruits pepper developed in the rest of mixtures evaluated. Equally, this range outperformed in at least for a $12.3 \%$ to the range of TSS of the fruits of bell pepper, $c v$. California, fertilized with 50 y $150 \mathrm{~g} \mathrm{VC} \cdot$ plant $^{-1}$, developed under field conditions by Hernández-Fuentes et al. [25]. On the other hand, TSS recorded in the mixtures M1 and M2 were greatly exceded by range, 9.65 and 10.75 ${ }^{\circ}$ Brix, registered by Aminifard et al. [40], during the developed of pepper, using five levels, 0, 50, 200, 350 and $500 \mathrm{~kg} \cdot \mathrm{ha}^{-1}$ Fulvic Acid fertilizer 70.0\%, under field conditions.

The TSS content registered in pepper fruits in the three of different mixtures evaluated M3, M4 and M12, they were coincided with the range of 3.0 to $4.0{ }^{\circ}$ Brix established by the NMX-F-039-1981 standard [41], as optimal soluble solids content. In the remaining mixtures the fruits of sweet pepper registered an TSS above the higest value of this standard (Figure 3 ).

Finally and in general terms, the improvement of fruits quality of bell pepper registered in the variables evaluated in this experiment, in accordance with Rajbir et al. [42] may be attributed to better growth of plant at different rate and sources of organic manures, which might have favoured the production of better quality fruits.

\section{Conclusion}

The organic manures enhance the quality of the fruits of pepper developed under greenhouse conditions. Unused synthetic fertilizers during the growing season and the fact that achieved its growth cycle suggest that the different types of mixtures: VC, SC, and CG with RS can manage the nutrient demand of pepper, due to its physical, chemical and biological characteristics. Thus, the idea that organic manures have the potential to support the development of plant species is strengthened when are used as part of the growing media. Then, these results support organic agriculture as an alternative for people who wish to consume quality fruits that ensures health. Finally, this study showed that the organic manures (VC, SC, CG) mixtured with RS in different ratios had a significant effect on the content of total phenolic compounds in pepper fruits, Mecate F1 variety, developed under greenhouse conditions.

\section{Acknowledgements}

This research was supported by a grant of the Universidad Autónoma Agraria Antonio Narro, with the code 1310-8251-2751.

\section{References}

[1] Horrigan, H., Lawrence, R.S. and Walke, P. (2002) How Sustainable Agriculture Can Address the Environmental and Human Health Harms of Industrial Agriculture. Environmental Health Perspectives, 110, 445-456. https://doi.org/10.1289/ehp.02110445

[2] Fortis-Hernández, M., Preciado-Rangel, P., García-Hernández, J.L., Navarro-Bravo, A., Antonio-González, J. and Omaña-Silvestre, J.M. (2012) Organic Substrates in the Production of Sweet Pepper. Revista Mexicana de Ciencias Agrarias, 3, 1203-12161. 
[3] Selahle, K.M., Sivakumar, D., Jifon, J. and Soundy, P. (2015) Postharvest Responses of Red and Yellow Sweet Peppers Grown under Photo-Selective Nets. Food Chemistry, 173, 951956. https://doi.org/10.1016/j.foodchem.2014.10.034

[4] Lake, I.R., Hooper, L., Abdelhamid, A., Bentham, G., Boxall, A.B.A., Draper, A., FairweatherTait, S., Hulme, M., Hunter, P.R., Nichols, G. and Waldron, K.W. (2012) Climate Change and Food Security: Health Impacts in Developed Countries. Environmental Health Perspectives, 120, 1520-1526. https://doi.org/10.1289/ehp.1104424

[5] Cardeñosa, V., Barreira, J.C.M., Barros, L., Arenas-Arenas, F.J., Moreno-Rojas, J.M. and Ferreira, I.C.F.R. (2015) Variety and Harvesting Season Effects on Antioxidant Activity and Vitamins Content of Citrus sinensis Macfad. Molecules, 20, 8287-8302.

https://doi.org/10.3390/molecules20058287

[6] Johansson, E., Hussain, A., Kuktaite, R., Andersson, S.C. and Olsson, M.E. (2014) Contribution of Organically Grown Crops to Human Health. International Journal of Environmental Research and Public Health, 11, 3870-3893. https://doi.org/10.3390/ijerph110403870

[7] Ramos-Agüero, D. and Terry-Alfonso, E. (2014) Generalities of the Organic Manures: Bocashi's Importance Like Nutritional Alternative for Soil and Plants. Cultivos Tropicales, 35, 52-59.

[8] Faezah-Omar, N., Aishah-Hassan, S., Kalsom-Yusoff, U., Psyquay-Abdullah, N.A., MegatWahab, P.E. and Rani-Sinniah, U. (2012) Phenolics, Flavonoids, Antioxidant Activity and Cyanogenic Glycosides of Organic and Mineral-base Fertilized Cassava Tubers. Molecules, 17, 2378-2387. https://doi.org/10.3390/molecules17032378

[9] Ibrahim, M.H., Jaafar, H.Z.E., Karimi, E.K. and Ghasemzadeh, A. (2013) Impact of Organic and Inorganic Fertilizers Application on the Phytochemical and Antioxidant Activity of Kacip Fatimah (Labisia pumila Benth). Molecules, 18, 10973-10988.

https://doi.org/10.3390/molecules180910973

[10] Dumas, Y., Dadomo, M., Di-Lucca, G. and Grolier, P. (2003) Effects of Environmental Factors and Agricultural Techniques on Antioxidant Content of Tomatoes. Journal of the Science of Food and Agriculture, 83, 369-382. https://doi.org/10.1002/jsfa.1370

[11] Ilic, Z., Ben-Yosef, A., Partzelan, Y., Alkalai-Tuvia, S. and Fallik, E. (2008) Total Antioxidant Activity (TAA) of Bell Pepper during Prolonged Storage on Low Temperatura. Journal of Agricultural Science, 53, 3-12.

[12] Blažková, J., Hlušičková, L. and Blažek, J. (2002) Fruit Weight, Firmness and Soluble Solids Content during Ripening of Karešova cv. Sweet Cherry. Horticultural Science (Prague), 29, 92-98.

[13] Lima-e-Silva, P.S., Antonio, R.P., Aires-Dantas, D. and de Sousa-Nunes, H.H. (2006) Juice Extraction for Total Soluble Solids Content Determination in Melón. Revista Caatinga, 19, 268-271.

[14] Mahmood, T., Anwar, F., Abbas, M., Boyce, M.C. and Nazamid-Saari, N. (2012) Compositional Variation in Sugars and Organic Acids at Different Maturity Stages in Selected Small Fruits from Pakistan. International Journal of Molecular Sciences, 13, 1380 1392. https://doi.org/10.3390/ijms13021380

[15] Abrameto, M.A., Pozzo-Ardizzi, C.M., Gil, M.L. and Molina, L.M. (2010) Analysis of Methodologies for the Study of Composition and Biochemical Carbohydrate Changes in Harvest and Postharvest Onion Bulbs. International Journal of Experimental Botany, 79, 123-132.

[16] Ibrahim, M.H., Jaafar, H.Z.E., Rahmat, A. and Rahman, Z.A. (2011) The Relationship between Phenolics and Flavonoids Production with Total Non Structural Carbohydrate and 
Photosynthetic Rate in Labisia pumila Benth. under High $\mathrm{CO}_{2}$ and Nitrogen Fertilization. Molecules, 16, 162-174. https://doi.org/10.3390/molecules16010162

[17] Medina-Juárez, L.A., Molina-Quijada, D.M.A., Del-Toro-Sánchez, C.L., González-Aguilar, G.A. and Gámez-Meza, N. (2012) Antioxidant Activity of Peppers (Capsicum annuum L.) Extracts and Characterization of Their Phenolic Constituents. Interciencia, 37, 588-593.

[18] Howard, L.R., Talcott, S.T., Brenes, C.H. and Villalon, B. (2000) Changes in Phytochemical and Antioxidant Activity of Selected Pepper Cultivars (Capsicum Species) as Influenced by Maturity. Journal of Agricultural and Food Chemistry, 48, 1713-1720. https://doi.org/10.1021/jf990916t

[19] Hallmann, E. and Rembiałkowska, E. (2012) Characterisation of Antioxidant Compounds in Sweet Bell Pepper (Capsicum annuum L.) under Organic and Conventional Growing Systems. Journal of the Science of Food and Agriculture, 92, 2409-2415. https://doi.org/10.1002/jsfa.5624

[20] Schmidt, R.H.J. (1989) The Arid Zones of Mexico: Climatic Extremes and Conceptualization of the Sonoran Desert. Journal of Arid Environments, 16, 241-256.

[21] Ayers, R.S. and Westcot, D.W. (1994) Water Quality for Agriculture. FAO Irrigation and Drainage Paper 29, Revision 1, FAO, Rome, 174 p.

[22] Márquez-Hernández, C., Cano-Ríos, P., Chew-Madinaveitia, Y.I., Moreno-Reséndez, A. and Rodríguez-Dimas, N. (2006) Substrates in the Organic Production of Greenhouse Cherry Tomato. Revista Chapingo Serie Horticultura, 12, 183-189.

[23] Atiyeh, R.M., Arancon, N., Edwards, C.A. and Metzger, J.D. (2000) Influence of Earthworm-Processed Pig Manure on the Growth and Yield of Greenhouse Tomatoes. Bioresource Technology, 75, 175-180. https://doi.org/10.1016/S0960-8524(00)00064-X

[24] Bansal, S. and Kapoor, K.K. (2000) Vermicomposting of Crop Residues and Cattle Dung with Eisenia foetida. Bioresource Technology, 73, 95-98. https://doi.org/10.1016/S0960-8524(99)00173-X

[25] Hernández-Fuentes, A.D., Campos-Montiel, R. and Pinedo-Espinoza, J.M. (2010) Postharvest Behavior of Bell Pepper (Capsicum annum L.) Variety California by the Effect of Chemical Fertilization and Appliance of Lombrihumus. Revista Iberoamericana de Tecnología Postcosecha, 11, 82-91.

[26] Singleton, V.L., Orthofer, R. and Lamuela-Raventos, R.M. (1999) Analysis of Total Phenols and Other Oxidation Substrates and Antioxidants by Means of Folin-Ciocalteu Reagent. Methods Enzymological, 299, 152-178. https://doi.org/10.1016/S0076-6879(99)99017-1

[27] Molyneux, P. (2004) The Use of the Stable Free Radical Diphenylpicrilhydracyl (DPPH) for Estimating Antioxidant Activity. Journal of Science and Technology, 26. 211-219.

[28] Olivares-Sáenz, E. (1993) Experimental Design Software. V. 2.4. Facultad de Agronomía-UANL, Marín.

[29] Helmja, K., Vaher, M., Gorbatšova, J. and Kaljurand, M. (2007) Characterization of Bioactive Compounds Contained in Vegetables of the Solanaceae Family by Capillary Electrophoresis. Proceedings of the Estonian Academy of Sciences, 56, 172-186.

[30] Navarro, J.M., Flores, P., Garrido, C. and Martínez, V. (2006) Changes in the Contents of Antioxidant Compounds in Pepper Fruits at Different Ripening Stages, as Affected by Salinity. Food Chemistry, 96, 66-73. https://doi.org/10.1016/j.foodchem.2005.01.057

[31] Tzortzakis, N., Gouma, S., Dagianta, E., Saridakis, C., Papamichalaki, M., Goumas, D. and Manios, T. (2012) Use of Fertigation and Municipal Solid Waste Compost for Greenhouse Pepper Cultivation. Scientific World Journal, 2012, Article ID: 973193. https://doi.org/10.1100/2012/973193 
[32] Kevers, C., Falkowski, M., Tabart, J., Defraigne, J.O., Dommes, J. and Pincemail, J. (2007) Evolution of Antioxidant Capacity during Storage of Selected Fruits and Vegetables. Journal of Agricultural and Food Chemistry, 55, 8596-8603. https://doi.org/10.1021/jf071736j

[33] Díaz-Méndez, H.A., Preciado-Rangel, P., Álvarez-Reyna, V.P., Fortis-Hernández, M., García-Hernández, J.H. and Sánchez-Chávez, E. (2014) Organic Production and Antioxidant Capacity of Cucumber Fruit. ITEA, 110, 335-342.

[34] Alvarez-Parrilla, E., de La Rosa, L.A., Amarowicz, R. and Shahidi, F. (2011) Antioxidant Activity of Fresh and Processed Jalapeño and Serrano Peppers. Journal of Agricultural and Food Chemistry, 59, 163-173. https://doi.org/10.1021/jf103434u

[35] Blanco-Ríos, A.K., Medina-Juárez, L.A., González-Aguilar, G.A. and Gámez-Meza, N. (2013) Antioxidant Activity of the Phenolic and Oily Fractions of Different Sweet Bell Peppers. Journal of the Mexican Chemical Society, 57, 137-143.

[36] Aminifard, M.H., Aroiee, H., Azizi, M., Nemati, H. and Jaafar, H.Z.E. (2013) Effect of Compost on Antioxidant Components and Fruit Quality of Sweet Pepper (Capsicum annuum L.). Journal of Central European Agriculture, 14, 525-534.

https://doi.org/10.5513/JCEA01/14.2.1232

[37] Chassy, A.W., Bui, L., Renaud, E.N.C., van Horn, M. and Mitchell, A.E. (2006) Three-Year Comparison of the Content of Antioxidant Microconstituents and Several Quality Characteristics in Organic and Conventionally Managed Tomatoes and Bell Peppers. Journal of Agricultural and Food Chemistry, 54, 8244-8252. https://doi.org/10.1021/jf060950p

[38] Abu-Zahra, T.R. (2014) A Comparative Study of Sweet Pepper Fruits Nutritional Composition Produced under Conventional and Organic Systems. International Journal of Agriculture Sciences, 10, 8-14.

[39] Fawzy, Z.F., El-Bassiony, A.M., Yunsheng, L., Zhu, O. and Ghoname, A.A. (2012) Effect of Mineral, Organic and Bio-N Fertilizers on Growth, Yield and Fruit Quality of Sweet Pepper. Journal of Applied Sciences Research, 8, 3921-3933.

[40] Aminifard, M.H., Aroiee, H., Nemati, H., Azizi, M. and Jaafar, H.Z.E. (2012) Fulvic Acid Affects Pepper Antioxidant Activity and Fruit Quality. African Journal of Biotechnology, 11, 13179-13185.

[41] NMX-F-039-1981 (1981) Foods for Humans. Canned Sweet Peppers. Normas Mexicanas. Dirección General de Normas. 5 p. http://www.colpos.mx/bancodenormas/nmexicanas/NMX-F-039-1981.PDF

[42] Rajbir, S., Sharma, R.R., Satyendra, K., Gupta, R.K. and Patil, R.T. (2008) Vermicompost Substitution Influences Growth, Physiological Disorders, Fruit Yield and Quality of Strawberry (Fragaria $\times$ ananassa Duch.). Bioresource Technology, 99, 8507-8511. https://doi.org/10.1016/j.biortech.2008.03.034 
Submit or recommend next manuscript to SCIRP and we will provide best service for you:

Accepting pre-submission inquiries through Email, Facebook, LinkedIn, Twitter, etc. A wide selection of journals (inclusive of 9 subjects, more than 200 journals)

Providing 24-hour high-quality service

User-friendly online submission system

Fair and swift peer-review system

Efficient typesetting and proofreading procedure

Display of the result of downloads and visits, as well as the number of cited articles

Maximum dissemination of your research work

Submit your manuscript at: http://papersubmission.scirp.org/

Or contact fns@scirp.org 